\title{
Lettau's Contribution to the Obukhov Length Scale: A Scientific Historical Study
}

\author{
Thomas Foken $^{1}$ (D) Michael Börngen ${ }^{2}$
}

Received: 17 July 2020 / Accepted: 6 February 2021 / Published online: 29 March 2021

(c) The Author(s) 2021

\begin{abstract}
It has been repeatedly assumed that Heinz Lettau found the Obukhov length in 1949 independently of Obukhov in 1946. However, it was not the characteristic length scale, the Obukhov length $L$, but the ratio of height and the Obukhov length $(z / L)$, the Obukhov stability parameter, that he analyzed. Whether Lettau described the parameter $z / L$ independently of Obukhov is investigated herein. Regardless of speculation about this, the significant contributions made by Lettau in the application of $z / L$ merit this term being called the Obukhov-Lettau stability parameter in the future.
\end{abstract}

Keywords Heinz Lettau · History of Meteorology · Micrometeorology · Obukhov length · Obukhov stability parameter

\section{Introduction}

Heinz Lettau (1909-2005) was Professor of Meteorology at the University of Wisconsin from 1957 to 1980 . He is considered the founder of the term planetary boundary layer (Sutton 1953), first published in Lettau (1939). Most of his publications deal with the atmospheric (planetary) boundary layer. For example, he was able to determine its essential properties by reworking the so-called Leipzig wind profile of Mildner (1932), as described in Lettau (1950). His contributions to atmospheric surface-layer research are relatively small, although, with the O'Neill experiment in 1953, he made a fundamental contribution to experimental boundary-layer research involving the layers near the ground (Lettau and Davidson 1957; Lettau 1990). In preparing this experiment, two years after moving from Germany to the USA in 1947 (Lettau 1990), he published a compilation of the state of knowledge on the atmospheric surface layer (Lettau 1949). In this work, a parameter $y$ is inserted relatively abruptly that closely corresponds to the Obukhov stability parameter $z / L$ (where $z$ is the height and $L$ is the Obukhov length) which is commonly used today (Fig. 1). As shown here, Lettau never explicitly stated the Obukhov length $L$ and its

Thomas Foken

thomas.foken@uni-bayreuth.de

1 Bayreuth Center of Ecology and Environmental Research, University of Bayreuth, 95447 Bayreuth, Germany

2 Institute of Geophysics and Geology, University Leipzig, 04103 Leipzig, Germany 
Another non-dimensional function of height, adiabatic mixing velocity and heat flux may be defined by

$$
y=\frac{g L k\left(z+z_{0}\right)}{T_{m} c_{p} \rho w_{a}^{*}{ }^{3}}
$$

which brings Eq. (38) to the very convenient form

$$
y=-x /(1+x)^{2}
$$

It must be pointed out that $y$ is defined proportional to the heat flux and independent of the gradient of potential temperature, while $x$ is defined proportional to the gradient of potential temperature and independent of the heat flux.

Fig. 1 Definition of the parameter $y$ on page 28 of Lettau (1949)

meaning. This raises the question of whether Lettau developed this parameter himself or if he had access to Obukhov (1946; English translation Obukhov 1971) through his connections in Germany, in particular to the Central Meteorological Observatory in Potsdam, which was located after World War II in the Soviet occupation zone. This fundamental work of Alexander Mikhailovich Obukhov (see Yaglom 1990) was originally written in 1943, see Businger and Yaglom (1971). The above question, which is examined below, also requires insights into the life of Heinz Lettau in the period before, during, and after the war.

\section{The Life of Heinz Lettau, with a Focus on the 1930s and 1940s}

Heinz Helmut Max Lettau was born on 4 November 1909 in Königsberg, East Prussia (today Kaliningrad, Russia) into a merchant family. After completing a broad education in mathematics, physics, and geophysics, including meteorology, at the universities of Königsberg, Frankfurt am Main, and Leipzig, he received his doctorate in 1931 at the Geophysical Institute of the University of Leipzig (Weickmann and Börngen 2013) under Ludwig Weickmann (1882-1961) with a thesis on the 36-day air pressure wave. At this institute he met Katharina Dörffel (1910-2008), who also received her academic training at the Geophysical Institute, and they married in 1937. After a short period at the Geodetic Institute in Potsdam, he was Weickmann's assistant from 1933 to 1938, during which his workplace was at the Geophysical Observatory Collm. During this time, he wrote his habilitation thesis on the horizontal double pendulum (Lettau 1937) and his well-known book Atmospheric Turbulence (published in Leipzig in 1939). In 1938, he was appointed head of the Geophysical Observatory Gross Raum (today Rjabinowka) at the University of Königsberg and lectured in geophysics and meteorology.

After the outbreak of the Second World War, he was assigned to the Central Weather Service Group (ZWG), the main weather analysis and forecasting centre of the German Air Force, located in Wildpark near Potsdam, along with other outstanding meteorologists. Heads of the ZWG were Kurt Diesing (1885-1943) and, after his death, from August 1943 Werner Schwerdtfeger (1909-1985). In 1943, Lettau was offered a professorship at the University of Graz (Austria), but was unable to occupy the post, and the appointment was to be later revoked by the governor of the state of Styria after the end of the war. In the same year 
(1943), he was transferred to an air brigade under Colonel Max Wachtel (1897-1982). He was tasked with providing ballistic winds based on wind-profile and turbulence data for V-1 rocket launches, first at the Air Force test facility in Peenemünde and from spring 1944 in northern France. During an inspection trip to Rennes, he was taken prisoner of war by the Americans on 3 August 1944. After his release, he worked until 1947-again under Weickmann - as head of the scientific department at the Weather Service in the US zone in Bad Kissingen, before emigrating to the USA. He worked there at the Massachusetts Institute of Technology (Cambridge) and from 1957 to 1980 at the University of Wisconsin-Madison. He supervised numerous doctoral (more than 20) and master's theses (almost 30), and authored nearly 180 publications (a few are mentioned in the references).

Lettau was honoured both in the USA (becoming Fellow of the American Meteorological Society and receiving the Carl-Gustav Rossby Research Medal) and in Germany (Alfred Wegener Medal of the German Meteorological Society). He was a member of the Editorial Boards of Gerlands Beiträge zur Geophysik (until 1944) and Boundary-Layer Meteorology after its foundation in 1970. Heinz Lettau died on 3 August 2005 in Mount Pleasant, South Carolina. (Sources: Archive of the Leipzig University-UAL; Poggendorf 1959, 2003; Schwerdtfeger and Lettau 1986; Lettau 2004; Keller et al. 2008).

As suggested below, Lettau must have been aware of a few details of Obukhov's (1946) work as former colleagues from the ZWG or those in Potsdam and Leipzig (both in the Soviet sector of Germany) may have informed him. Before Lettau emigrated to the USA, from 1946 until the German currency reform in June 1948, contacts between the Western sectors and the Soviet sector in Germany were also quite possible. However, the exact manner in which this could have occurred is pure speculation.

\section{State of Surface-Layer Theory at the End of the 1940s}

Knowledge in micrometeorology was quite considerable at the time Obukhov (1946) und Lettau (1949) were published. The phenomenological understanding of the micrometeorological processes was especially well developed (Geiger 1927) as well as the understanding of the influence of plant-covered surfaces (Paeschke 1937). Also, the first heat balance of the Earth was available (Albrecht 1940) along with the first ideas of vortex structures near the Earth's surface (Albrecht 1943).

The theory of exchange processes was developed based on hydrodynamic considerations. The separation of mean motions and turbulent fluctuations had already been known for a long time as Reynolds decomposition (Reynolds 1895), while considerable progress was made with the definition of the Richardson number (Richardson 1920) and Prandtl's mixing-length approach (Prandtl 1925). The history of these findings is documented in Davidson et al. (2011). Relevant for their application in meteorology was the introduction of the "Austausch" (exchange) coefficient $A$ by Schmidt (1925),

$$
\tau=A \frac{\partial u}{\partial z}=\rho K \frac{\partial u}{\partial z}
$$

with the turbulent stress $\tau$, the air density $\rho$, the mean wind speed $u$, and the turbulent diffusion coefficient $K$.

This was an assumption for the atmosphere that followed the laws of hydrodynamics. At the same time, it was clear that the exchange coefficient had to be subject to strong temporal variations. Lettau (1939) defined an "apparent" exchange coefficient depending on 
the mixing length or the surface roughness. In Lettau (1941), he tried to vary the exchange coefficient in the diurnal cycle using periodic functions. Furthermore, a second maximum of the exchange coefficient at night was discussed (Lettau 1942; Robitzsch 1942), an effect that is nowadays found to be related to breaking gravity waves and low-level jets. The disadvantage of all these attempts was the lack of suitable observations.

Two problems of that time are specifically extensively quoted: the determination of the von Kármán constant $\kappa$ and possible deviations from the logarithmic shape in velocity and temperature profiles. In relation to the first problem, Montgomery $(1943,1948)$ proposed a value of $\kappa=0.45$ for the atmosphere in contrast to previous suggestions of 0.38 or 0.40 . For the second problem, a dependence of the turbulent fluxes on stratification was found by Rossby and Montgomery (1935), and applied by Sverdrup (1936) as described in Sect. 4.1. Both Lettau (1949) and Obukhov (1946) made a reference to Sverdrup (1936), and Lettau (1939) made a reference to both Rossby and Montgomery (1935) and Sverdrup (1936). Most of the other papers did not mention these calculations; for example, Thornthwaite and Kaser (1943) found that, in the case of stable stratification, wind profiles no longer follow the logarithmic law. Sheppard (1947) found similar effects, with a part of the wind profile closest to the ground still following the logarithmic law, as Montgomery (1947) discussed which is in agreement with the later published theoretical interpretation by Monin and Obukhov (1954).

Richardson (1920) estimated the applied mechanical work of the shear stresses and the energy loss occurring with the thermal lifting of air parcels and the working of parcels against each other, which can be described by the ratio (Prandtl 1932)

$$
-\frac{\frac{g}{\rho} \frac{\partial \rho}{\partial z}}{\left(\frac{\partial u}{\partial z}\right)^{2}}
$$

where $g$ is the acceleration due to gravity, which resulted in the Richardson number,

$$
R i=\frac{\frac{g}{\theta} \frac{\partial \theta}{\partial z}}{\left(\frac{\partial u}{\partial z}\right)^{2}},
$$

with $\theta$ being the potential temperature. In addition to Richardson and Prandtl, Taylor and Goldstein also investigated the problem (Prandtl 1932). Lettau (1939) followed the formulation of Prandtl and showed Eq. 2 explicitly. However, in Lettau (1949), the basis of the Richardson number is no longer presented. In contrast, Obukhov (1946) quotes Goldstein's textbook (Goldstein 1938).

\section{Lettau's Contributions to Surface-Layer Theory}

\subsection{Lettau's Definition of the Obukhov Stability Parameter}

While Lettau (1939) adhered strictly to the nomenclature given by Prandtl and Richardson, the accessibility of the work under consideration here (Lettau 1949) is relatively difficult, since Lettau (1949) used primes for differentiation with respect to height and used the French accent grâve for turbulent fluctuations (while the present work follows the notation 
that is common today). Furthermore, Lettau's definition for the covariance for non-isotropic turbulence (grey-shaded equations and the sign of fluxes and parameters are identical to the original reference)

$$
\overline{u^{\prime} w^{\prime}}=u w^{*}
$$

is different from the other literature, where $u^{*}$ is referred to as a friction velocity, and $w^{*}$ as a mixing velocity, where $u^{\prime}$ and $w^{\prime}$ are turbulent fluctuations of the streamwise and vertical velocity components. According to the definition of isotropic turbulence (Taylor 1935), "In isotropic turbulence the average value of any function of the velocity components, defined in relation to a given set of axes, is unaltered if the axes of reference are rotated in any manner" and the associated assumption of an adiabatic atmosphere (subscript $a$ ) follows $u_{a}^{*}=w_{a}^{*}$ and thus for the stress

$$
\tau_{a}=\rho u_{a}^{* 2}=\rho w_{a}^{* 2} .
$$

Confusing in this context is the definition of the mixing length $l$ with the local averaged vertical velocity component $w^{*}$ in Lewis (1997) about the balloon experiments of Lettau and Schwerdtfeger, for the time interval $\tau$ (not stress!)

$$
l=w^{*} \tau=\int_{t}^{t+\tau} w^{\prime} \mathrm{d} t .
$$

Lettau and Schwerdtfeger (1933a, b) used this approach to calculate the exchange coefficients by Hesselberg (1929) and Ertel (1932). However, they used the symbol $\zeta^{*}$ and not $w^{*}$. The symbol and the definition differ. In Lettau (1949), there is no reference to it.

For non-isotropic conditions, Lettau assumed that the ratio of mixing velocity and mixing length does not depend on the stratification

$$
\frac{w^{*}}{l}=\frac{w_{a}^{*}}{l_{a}} .
$$

The difference between adiabatic conditions and conditions with existing stratification is described by the buoyancy force. The term $w_{a}^{* 2} / l_{a}$ describes the vertical component of turbulent acceleration under adiabatic conditions. Thus follows

$$
\frac{w^{* 2}}{l}=\frac{w_{a}^{* 2}}{l_{a}}-\frac{g l \frac{\partial \theta}{\partial z}}{T_{m}}
$$


with $T_{\mathrm{m}}$ as absolute mean temperature in the surface layer. From Eqs. 7 and 8, it follows that

$$
\frac{l}{l_{a}}=\frac{1}{1+\frac{g l_{a}^{2} \frac{\partial \theta}{\partial z}}{T_{m} w_{a}^{* 2}}}
$$

Lettau used the notation

$$
x=\frac{g l_{a}^{2} \frac{\partial \theta}{\partial z}}{T_{m} w_{a}^{* 2}}=\frac{g \frac{\partial \theta}{\partial z}}{T_{m}\left(\frac{\partial u}{\partial z}\right)_{a}^{2}}
$$

and defined relationships between adiabatic and non-adiabatic conditions, for instance for the mixing length

$$
l=l_{a} /(1+x)
$$

He provided analogous relationships for the mixing velocity, the exchange coefficient ( $A$, see Eq. 1), and the sensible heat flux (for which he used the symbol $L$ instead of $H$ in the following)

$$
H=-c_{p} A \frac{\partial \theta}{\partial z} /(1+x)^{2}
$$

where $c_{\mathrm{p}}$ is the specific heat at constant pressure. Besides that, he related $x$ to the Richardson number as

$$
x=\frac{\left(\frac{\partial u}{\partial z}\right)^{2}}{\left(\frac{\partial u}{\partial z}\right)_{a}^{2}} R i
$$

At this point, Lettau introduced another dimensionless function of height, the adiabatic mixing velocity, and the sensible heat flux without further explanation (with the roughness length $z_{0}$, see Fig. 1) 


$$
y=\frac{g H \kappa\left(z+z_{0}\right)}{T_{m} \rho c_{p} w_{a}^{* 3}}
$$

which is nearly identical to the Obukhov stability parameter $z / L$ defined by Eq. 19 below. For adiabatic and isotropic conditions, $w_{a}^{*}$ according to Eq. 5- see also Eq. 26a in Lettau (1949) - is equivalent to the friction velocity in today's definition. From Eqs. 11 and 12 follows the relation between $x$ and $y$,

$$
y=-\frac{x}{(1+x)^{2}}
$$

Rossby and Montgomery (1935) used a similar approach to derive an equation for the vertical wind-speed profile, which means that they separated the adiabatic part from the stratification-influenced part. However, they did not separate the covariance $\overline{u^{\prime} w^{\prime}}$ according to Eq. 4. Finally, they found the relationship

$$
\frac{\mathrm{d} u}{\mathrm{~d} z}=\frac{1}{\kappa\left(z+z_{0}\right)} \sqrt{\frac{\tau}{\rho}} \sqrt{\frac{1}{2}+\frac{1}{2} \sqrt{1+\frac{4 x^{2}\left(z+z_{0}\right)^{2}}{\left(\frac{1}{\kappa} \sqrt{\frac{\tau}{\rho}}\right)^{2}}} .}
$$

With the definition by Rossby and Montgomery (1935)

$$
x^{2}=\beta \frac{g}{T} \frac{\mathrm{d} \theta}{\mathrm{d} z}=\beta \frac{g}{T} \frac{H}{c_{p} \rho \kappa u_{*}\left(z+z_{0}\right)},
$$

where $\beta$ is an unknown dimensionless coefficient, it follows that

$$
\frac{4 x^{2}\left(z+z_{0}\right)^{2}}{\left(\frac{1}{\kappa} \sqrt{\frac{\tau}{\rho}}\right)^{2}}=4 \beta \kappa\left(z+z_{0}\right) \frac{g}{T} \frac{\frac{H}{c_{p} \rho}}{u_{*}^{3}} \approx 4 \beta \kappa z \frac{g}{T} \frac{\frac{H}{c_{p} \rho}}{u_{*}^{3}}=4 \beta \frac{z}{L} .
$$

Rossby and Montgomery (1935) used Eq. 16 to calculate the deviation of the nonadiabatic wind profile from the logarithmic wind profile for nearly isothermal conditions, and Sverdrup (1936) did the same for non-isothermal conditions. But they did not separate the term on the right-hand side of Eq. 18 and investigate its properties.

According to the current nomenclature (including the negative sign of $L$ for unstable conditions with $H>0$, no distinction between the friction velocity and the mixing velocity, and adiabatic conditions), from Eq. 14 with $z \gg z_{0}$ and from Eq. 18 with $\beta=0.25$, what follows is exactly the Obukhov stability parameter with the Obukhov length $L$

$$
\frac{z}{L}=-\frac{z \kappa \frac{g}{T_{m}} \frac{H}{\rho c_{p}}}{u_{*}^{3}} .
$$


However, this simplification is not in complete agreement with the mixing velocity according to Lettau (1949), because Eq. 5 assumes adiabatic conditions and isotropy, while in Eq. $19 H \neq 0$ is possible. Businger (1955) already pointed out this problem in the discussion of Eq. 8. However, Obukhov (1946) and Monin and Obukhov (1954) give a range for $z<<L$ where the exchange conditions differ little from exchange conditions in a neutrally-stratified atmosphere independent of the magnitude of the sensible heat flux (sublayer of dynamic turbulence). Skeib (1980) (see also Foken and Skeib 1983) determined a critical height to which the assumption applies and which is $0.5 \mathrm{~m}$ to about $5 \mathrm{~m}$ depending on the stratification. Thus, it must be stated that the parameter $y$ according to Lettau (1949) and $z / L$ according to Obukhov (1946) are not exactly identical with respect to the definition, but are largely identical near the surface in the dynamical sublayer.

Monin and Obukhov (1954) also defined the Obukhov length as a function of the friction velocity, the sensible heat flux, and the buoyancy parameter $g / T_{m}$, but derived this relationship with the $\Pi$-theorem and not empirically. However, the relation between $x$ and $y$ or $R i$ and $z / L$ was first obtained by Lettau (1949), earlier than Monin and Obukhov (1954), and is still used today with little numerical difference for stable stratification (Businger et al. 1971)

$$
\begin{gathered}
z / L=R i \quad \text { for } R i<0, \\
z / L=\frac{R i}{1-5 R i} \quad \text { for } 0 \leq R i \leq 0.2=R i_{c} .
\end{gathered}
$$

\subsection{Obukhov's Definition of the Obukhov Length}

Obukhov (1946) also used Schmidt's exchange approach. Obukhov solved the problem of stratification by using a function of the Richardson number, $\varphi(R i)$, where in the neutral case $\varphi(0)=1$. It is interesting that Obukhov also began his derivation with two generalized velocities, the friction velocity (symbols according to Obukhov 1946)

$$
v_{*}=\sqrt{\tau / \rho}
$$

and the "thermal" mixing velocity

$$
u_{*}=q / c_{p} \rho T
$$

with the sensible heat flux $q$. [Remark: "thermal" mixing velocity, in Russian: скорость переноса тепла; in the English translation (Obukhov 1971) a formulation according to current usage was chosen: "heat flux velocity" with the symbol $u$, in Russian: скорость потока тепла]. This unusual use of $u_{*}$ may be confusing to the reader. Note that this also differs from Lettau's definition of the mixing velocity $w^{*}$. 
Obukhov did not make a distinction between isotropic and non-isotropic turbulence, and so for the Richardson number it follows that

$$
R i=\frac{1}{a} \kappa z \frac{g u_{*}}{v_{*}^{3}} \sqrt{\varphi(R i)},
$$

where $1 / a$ is the turbulent Prandtl number according to our present-day definition. The derivative with respect to height is

$$
\frac{\partial R i}{\partial z}=\frac{1}{a} \kappa \frac{g u_{*}}{v_{*}^{3}} \sqrt{\varphi(R i)}-\frac{1}{a} \kappa \frac{g u_{*}}{v_{*}^{3}} z \frac{\varphi^{\prime}(R i)}{2 \sqrt{\varphi(R i)}} .
$$

The value of the derivative at $z=0$ was defined by Obukhov as the scale of the height of the surface layer with dynamic turbulence
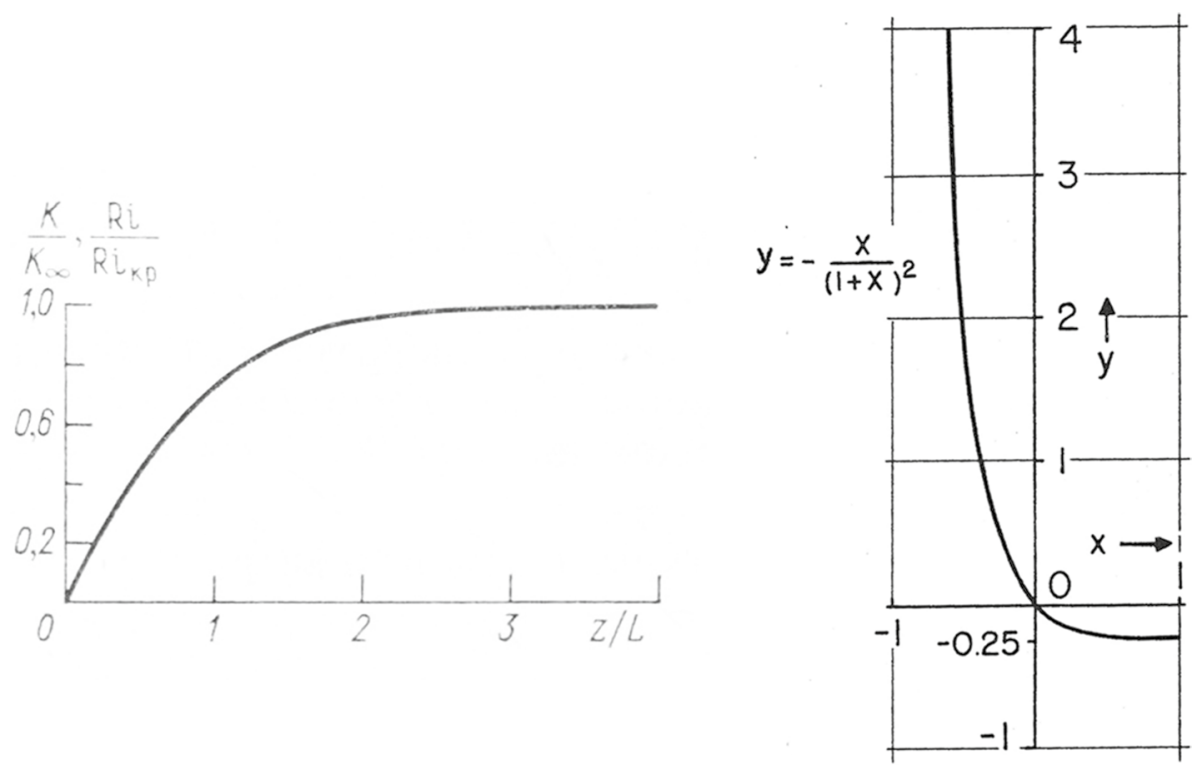

Fig. 2 Dependence of the parameter $z / L$ on the Richardson number in the case of stable stratification. Left: from Obukhov (1946); the Richardson number was normalized with the critical Richardson number and the ratio of exchange coefficient and maximum exchange coefficients. Right: from Lettau (1949); comparable to Obukhov (1946) by rotating the fourth quadrant by $90^{\circ}$, where $x=-R i$. The parameter $R i_{\mathrm{\kappa p}}$ is the critical Richardson number $R i_{\text {cr }}$ 


$$
L=\frac{1}{a} /\left(\frac{\partial R i}{\partial z}\right)_{z=0}=\frac{1}{\kappa} \frac{v_{*}^{3}}{g u_{*}}=\frac{1}{\kappa} \frac{v_{*}^{3}}{\frac{g}{T} \frac{q}{c_{p} \rho}},
$$

with $a=1$. For a discussion of the use of the turbulent Prandtl number and the von Kármán constant by different authors, see Foken (2006). The Obukhov length is significantly greater than the height of the surface layer for neutral stratification. A physical interpretation of $L$ was made by Bernhardt (1995), i.e., "the absolute value of the Obukhov length is equal to the height of an air column in which the production $(L<0)$ or the loss $(L>0)$ of turbulence kinetic energy (TKE) by buoyancy forces is equal to the dynamic production of TKE per volume unit at any height $z$ multiplied by $z$ ".

\subsection{Properties of the Obukhov Stability Parameter}

In the early $1950 \mathrm{~s}$, Lettau was obviously quite convinced of his scaling velocity $w_{a}^{*}$. However, when results of the O'Neill experiment of 1953 were published in 1957, references to $w_{a}^{*}$ were already missing (Lettau 1957,1990$)$ and it was not adopted by the community (Sutton 1953). Lettau's ideas are partly contradictory to the scaling of Batchelor (1950). This was explained by Inoue (1952) in a commentary to which Lettau (1952a) replied and specified his ideas. In particular, they referred to the extension of the scaling into the laminar domain and the application of Taylor's (1935) definition of isotropic turbulence for the atmosphere. Lettau again presented his ideas in a broader context in Lettau (1952b).

It is appropriate to look again at Obukhov (1946) and Lettau (1949) with regard to the further explanations. Both authors show an almost identical picture with the dependence between $R i$ and $z / L$ or $x$ and $y$, respectively (Fig. 2). It is noticeable that the range of validity for $z / L$ and $y$ was chosen to be relatively broad (as Lettau showed in another figure, even for $-5<y<15$ as well). In contrast, the range of validity of Monin and Obukhov's (1954) similarity theory for the surface layer today is given as $-1<z / L<1$ when defining the Obukhov length with the von Kármán constant and without the turbulent Prandtl number (Foken 2006), whereby influences of the mixed layer and the Coriolis force are certainly present (Johansson et al. 2001; Högström et al. 2002).

It must therefore be assumed that, based on his earlier works, Lettau always had the entire boundary layer in view. It is thus not unreasonable to define a thermal mixing velocity. This idea was also used by Zilitinkevich (1971) and Betchov and Yaglom (1971) for the convective atmospheric boundary layer, summarized by Kader and Yaglom (1990), and can be seen as an anticipation of Deardorff's (1970) scaling velocity for convective conditions, even if it is defined differently as.

$$
w_{*}=\left(\frac{g z_{i}}{\theta_{v}} \overline{w^{\prime} \theta_{v}^{\prime}}\right)^{1 / 3},
$$

where $z_{i}$ is the mixed-layer height, and $\theta_{v}$ is the virtual potential temperature. Interesting is the choice of the symbol for the Deardorff velocity, which is still valid today, even if there is no explicit reference to Lettau in Deardorff's work.

An essential application of the parameter $y$ (or $z / L$ ) is as a stability-dependent term in the profile equations for the momentum or heat exchange. Obukhov (1946) as well as 
Lettau (1949) tried this by modifying the exchange coefficient. In the case of Lettau, the following equation of exchange coefficient-using Eq. 10—was formulated as

$$
A=\frac{A_{a}}{(1+x)^{2}}=A_{a}\left(\frac{2 y}{\sqrt{1+4 y}-1}\right)^{2}-A_{a} \frac{2 y^{2}}{1+2 y-\sqrt{1+4 y}}
$$

because

$$
x=-1-\frac{1}{2 y}(1-\sqrt{1+4 y}) .
$$

Physically, only the root of the smaller absolute value is of interest.

Thus, Lettau has explicitly introduced the parameter $y$ (or $z / L)$ into the profile equations, similarly to Rossby and Montgomery (1935) and Sverdrup (1936). However, the formulation led to considerable problems in integration, and he developed the root expression as a power series.

In contrast, Obukhov modified the exchange coefficient with a function depending on the ratio of Richardson number and critical Richardson number $R i_{\mathrm{cr}}$.

$$
\varphi(R i)=\sqrt{1-R i / R i_{c r}} .
$$

In an intermediate step, Lettau formulated a parameter $\beta z / L$. However, this parameter was first introduced into the profile equations by Monin and Obukhov (1954) as a power series $1-\beta z / L$, the so-called universal function of the similarity theory of Monin and Obukhov.

Lettau (1956) used his formulation (Lettau 1952b) in comparison with observations and found a clearly better agreement than with the theory of Businger (1955), who preferred a purely modified mixing-length approach with references to Rossby and Montgomery (1935) and Lettau (1949). Therefore, Businger's approach has similarities to that of Lettau (1949) and contrasts to the statistical turbulence approaches of Batchelor (1950) and Inoue (1952).

\section{Conclusions}

A first conclusion is that Rossby and Montgomery (1935) were the first to find a term in the non-adiabatic profile equation that was similar to the Obukhov stability parameter $z / L$ and was applied by Sverdrup (1936). However, they did not explicitly discuss this parameter. Because Obukhov and Lettau were familiar with Sverdrup (1936), this term was not unknown to both. 
On the one hand the following assessment is hypothetical as arguments cannot be dismissed that Lettau knew at least several results of Obukhov's 1946 paper. On the other hand, Lettau's work of 1949 was certainly not completely unknown to Monin and Obuknov, see Monin and Obukhov (1954). A possible, albeit rather improbable, contact person in the years 1945 to 1948 could have been Prof. Hans Ertel, who from 1946 was Professor for Geophysics in Berlin (East), and Lettau used his exchange approach (1932). A further possible contact was Prof. Horst Philipps, with whom Lettau served, at least temporarily, within the Central Weather Service Group of the German Air Force during World War II. After 1946, Philipps was at the Meteorological Central Observatory Potsdam in the Soviet occupation zone. Philipps and Dr. Fritz Albrecht worked there on Soviet research projects (Möller 1963) investigating the heat balance of the Earth's surface (Albrecht 1950). Albrecht supported Lettau's balloon experiments with scientific devices (Lettau and Schwerdtfeger 1933b) and he used the Sverdrup (1936) approach for his own work (Albrecht 1940, 1943). In 1948, he emigrated to the western part of Germany and in 1949 for eight years to Australia, and later again back to Germany (Möller 1965; Foken and Spänkuch 1996).

It is also possible that the contents of Obukhov (1946), together with the publication of Kolmogorov's famous papers and Obukhov's supplementary paper (Kolmogorov 1941a, b; Obukhov 1941; Falkovich 2011), were brought to the English-speaking world by Batchelor 's (1947) contribution.

Obukhov's definition of two velocity scales is confusing, especially because one of these is the sensible heat flux normalized with the temperature (Eq. 23) and having the dimensions of a velocity. Lettau must have heard of this somehow and tried to define two scales of velocity, because he developed the "thermal" mixing velocity for $w^{*}$. This took him as far as the definition of the parameter $x$ (Richardson number) but not to the derivation of the parameter $y$, which he introduced rather speculatively, since he obviously knew about it.

In conclusion, it must be noted that Lettau never explicitly discussed the Obukhov length and thus had not recognized its universal character as Obukhov (1946) and Monin and Obukhov (1954). However, he was aware of the stability parameter $z / L$ and the properties of this function, so the work of 1949 can certainly be understood as a link between Obukhov (1946) and Monin and Obukhov (1954). It is significant that Lettau also never claimed to have found the Obukhov length, up to the award of the Alfred Wegener Medal in Germany in 1974, when, in a reference to a lecture by Neumann (1964), he is described as the second inventor of the Obukhov length (Wippermann 1974). In the 1974 laudation for the Carl-Gustaf Rossby Research Medal of the American Meteorological Society "his original concept of the stability length scale" was highlighted (AMS 1974) as well. In 1979, Lettau (1979) first obviously pointed out, with reference to Neumann's lecture and Stearns (1970), that he had derived a term with a similar meaning but with a different scaling in 1949. At least since 1971 (Businger and Yaglom 1971) it has been known in the English-speaking world that the length scale was proposed as a scaling parameter by Obukhov in 1946. Also, Businger and Yaglom (1971) wrote: "This length scale was later introduced independently by Lettau (1949)". Consequently, it can be said that Lettau investigated the fundamental properties of the stability parameter $z / L$ and it would be appropriate to name $z / L$ the Obukhov-Lettau stability parameter.

Acknowledgements The authors are grateful to Prof. Dr. Peter Hupfer, who was not only the doctoral supervisor of both authors, but also provided the inspiration for work on this paper. We would also like to thank the libraries of the German Meteorological Service (DWD) and of the University of Bayreuth for the supply of various references. We thank Andrey Grachev, Ankur Desai, and two anonymous reviewers for the valuable additional information they provided in order to supplement and clarify some parts of the manuscript. 
Funding Open Access funding enabled and organized by Projekt DEAL.

Open Access This article is licensed under a Creative Commons Attribution 4.0 International License, which permits use, sharing, adaptation, distribution and reproduction in any medium or format, as long as you give appropriate credit to the original author(s) and the source, provide a link to the Creative Commons licence, and indicate if changes were made. The images or other third party material in this article are included in the article's Creative Commons licence, unless indicated otherwise in a credit line to the material. If material is not included in the article's Creative Commons licence and your intended use is not permitted by statutory regulation or exceeds the permitted use, you will need to obtain permission directly from the copyright holder. To view a copy of this licence, visit http://creativecommons.org/licenses/by/4.0/.

\section{References}

Albrecht F (1940) Untersuchungen über den Wärmehaushalt der Erdoberfläche in verschiedenen Klimagebieten. Reichsamt Wetterdienst, Wiss Abh. Bd VIII, Nr 2:1-82

Albrecht F (1943) Turbulenzuntersuchungen. Meteorol Z 60:109-121

Albrecht F (1950) Untersuchung über den Wärmehaushalt der Erde und seine thermodynamische Bedeutung. Ber Dt Wetterdienstes US-Zone 17:1-70

AMS (1974) Annual awards, the Carl-Gustaf Rossby research medal. Bull Am Meteorol Soc 55:430

Batchelor GK (1947) Kolmogoroff's theory of locally isotropic turbulence. Math Proc Camb Phil Soc 43:533-559. https://doi.org/10.1017/S0305004100023793

Batchelor GK (1950) The application of the similarity theory of turbulence to atmospheric diffusion. QJR Meteorol Soc 76:133-146. https://doi.org/10.1002/qj.49707632804

Bernhardt K-H (1995) Zur Interpretation der Monin-Obuchovschen Länge. Meteorol Z 4:81-82. https://doi. org/10.1127/metz/4/1992/81

Betchov R, Yaglom AM (1971) Comments on the theory of similarity as applied to turbulence in an unstably stratified fluid. Izv. Akad. Nauk SSSR, Ser. Fiz. Atmos. i Okeana (Engl. translation). 7:829-832

Businger JA (1955) On the structure of the atmospheric surface layer. J Meteorol 12:553-561. https://doi. org/10.1175/1520-0469(1955)012\%3c0553:OTSOTA\%3e2.0.CO;2

Businger JA, Wyngaard JC, Izumi Y, Bradley EF (1971) Flux-profile relationships in the atmospheric surface layer. J Atmos Sci 28:181-189. https://doi.org/10.1175/1520-0469(1971)028\%3c0181:FPRITA\% 3e2.0.CO;2

Businger JA, Yaglom AM (1971) Introduction to Obukhov's paper "Turbulence in an atmosphere with a non-uniform temperature.” Bound-Layer Meteorol 2:3-6. https://doi.org/10.1007/BF00718084

Davidson PA, Kaneda Y, Moffatt K, Sreenivasan KR (eds) (2011) A voyage through turbulence. Cambridge University Press, Cambridge

Deardorff JW (1970) Preliminary results from numerical integrations of the unstable planetary boundary layer. J Atmos Sci 27:1209-1211. https://doi.org/10.1175/1520-0469(1970)027\%3c1209:PRFNIO\% 3e2.0.CO;2

Ertel H (1932) Allgemeine Theorie der Turbulenzreibung und des “Austausches." Sitzungsber Math-Phys Klasse Preuß Akad Wiss 26:436-445

Falkovich G (2011) The Russian school. In: Davidson PA et al (eds) A voyage through turbulence. Cambridge University Press, Cambridge, UK, pp 209-237

Foken T, Skeib G (1983) Profile measurements in the atmospheric near-surface layer and the use of suitable universal functions for the determination of the turbulent energy exchange. Bound-Layer Meteorol 25:55-62. https://doi.org/10.1007/BF00122097

Foken T, Spänkuch D (1996) Zum 100. Geburtstag von Fritz Albrecht. Mitt Dt Meteorol Ges. pp. 37-38

Foken T (2006) 50 years of the Monin-Obukhov similarity theory. Bound-Layer Meteorol 119:431-447. https://doi.org/10.1007/s10546-006-9048-6

Geiger R (1927) Das Klima der bodennahen Luftschicht Friedr. Vieweg \& Sohn, Braunschweig

Goldstein S (1938) Modern developments in fluid dynamics: an account of theory and experiment relating to boundary layers, turbulent motion and wakes. Clarendon Press, Oxford

Hesselberg T (1929) Ein neuer Ausdruck für den Austauschkoeffizienten. Ann Hydrogr Marit Meteorol 57:319-326

Högström U, Hunt JCR, Smedman A-S (2002) Theory and measurements for turbulence spectra and variances in the atmospheric neutral surface layer. Bound-Layer Meteorol 103:101-124. https://doi.org/10. 1023/A:1014579828712 
Inoue E (1952) Some remarks on Lettau's new theories of the atmospheric surface layer. J Meteorol 9:224225. https://doi.org/10.1175/1520-0469(1952)009\%3c0224:SROLNT\%3e2.0.CO;2

Johansson C, Smedman A, Högström U, Brasseur JG, Khanna S (2001) Critical test of Monin-Obukhov similarity during convective conditions. J Atmos Sci 58:1549-1566. https://doi.org/10.1175/15200469(2001)058\%3c1549:CTOTVO\%3e2.0.CO;2

Kader BA, Yaglom AM (1990) Mean fields and fluctuation moments in unstably stratified turbulent boundary layers. J Fluid Mech 212:637-662. https://doi.org/10.1017/S0022112090002129

Keller L, Martin J, Stearns C (2008) On the death of Professor Emeritus Heinz H. Lettau. University of Wisconsin, Faculty Document 2038

Kolmogorov AN (1941a) Lokalnaja struktura turbulentnosti v neschtschimaemoi schidkosti pri otschen bolschich tschislach Reynoldsa (The local structure of turbulence in incompressible viscous fluid for very large Reynolds numbers). Dokl AN SSSR 30:299-303

Kolmogorov AN (1941b) Rassejanie energii pri lokolno-isotropoi turbulentnosti (dissipation of energy in locally isotropic turbulence). Dokl AN SSSR 32:22-24

Lettau H, Schwerdtfeger W (1933a) Vertikalaustausch in unmittelbarer Berechnung. Meteorol Z 50:47-51

Lettau H, Schwerdtfeger W (1933b) Untersuchungen über atmospharische Turbulenz und Vertikalaustausch vom Freiballom aus. Teil I Meteorol Z 50:250-256

Lettau H (1937) Das Horizontaldoppelpendel. Z Geophys 13:25-33

Lettau H (1939) Atmosphärische Turbulenz. Akad. Verlagsges, Leipzig

Lettau H (1941) Über die Zeit- und Höhenabhängigkeit des Austauschkoeffizienten im Tagesgang innerhalb der Bodenschicht. Gerl Beitr Geophys 57:171-192

Lettau H (1942) Über das nächtliche Nebenmaximum beim täglichen Gang des vertikalen Austauschkoeffizienten im Zusammenhang mit meteorologischen Erscheinungen. Gerl Beitr Geophys 59:150-161

Lettau H (1949) Isotropic and non-isotropic turbulence in the atmospheric surface layer. Geophys Res Pap 1:1-86

Lettau H (1950) A Re-examination of the "Leipzig Wind Profile" considering some relations between wind and turbulence in the frictional layer. Tellus 2:125-129. https://doi.org/10.1111/j.2153-3490.1950. tb00321.x

Lettau H (1952a) Reply. J Meteorol 9:225-226. https://doi.org/10.1175/1520-0469(1952)009\%3c0225:R\% 3e2.0.CO;2

Lettau H (1952b) The present position of selected turbulence problems in the atmospheric boundary layer. Geophys Res Pap 19:49-95

Lettau H (1956) Note on the structure of the atmospheric surface layer. J Meteorol 13:507-509. https://doi. org/10.1175/1520-0469(1956)013\%3c0507:NOTSOT\%3e2.0.CO;2

Lettau HH (1957) Summary of non-dimensional characteristics of boundary layer theory. In: Lettau HH, Davidson B (eds) Exploring the atmosphere's first mile. Pergamon Press, London, pp 337-359

Lettau H (1979) Wind and temperature profile prediction for diabatic surface layers including strong inversion cases. Bound-Layer Meteorol 17:443-464. https://doi.org/10.1007/BF00118610

Lettau H (1990) The O’Neill experiment of 1953. Bound-Layer Meteorol 50:1-9

Lettau H (2004) Erinnerungen an die Leipziger Schule unter Weickmanns Leitung und an das Collm Observatorium. unpublished

Lettau HH, Davidson B (eds) (1957) Exploring the atmosphere's first mile. Pergamon Press, London

Lewis JM (1997) The Lettau-Schwerdtfeger balloon experiment: measurement of turbulence via austausch theory. Bull Am Meteorol Soc 78:2619-2635. https://doi.org/10.1175/1520-0477(1997)078\%3c2619: TLSBEM\%3e2.0.CO;2

Mildner P (1932) Über die Reibung in einer speziellen Luftmasse in den untersten Schichten der Atmosphäre. Beitr Phys freien Atmos 19:151-158

Möller F (1963) Horst Philipps †. Gerl Beitr Geophys 72:132-138

Möller F (1965) Nachruf auf Fritz Albrecht. Meteorol Rundschau 18:11

Monin AS, Obukhov AM (1954) Osnovnye zakonomernosti turbulentnogo peremesivanija v prizemnom sloe atmosfery (basic laws of turbulent mixing in the atmosphere near the ground). Trudy Geofiz Inst AN SSSR 24(151):163-187

Montgomery RB (1943) Generalization for cylinders of Prandtl' s linear assumption for mixing length. Ann N Y Acad Sci 44:89-103

Montgomery RB (1947) Comments on P. A. Sheppard's direct measurement of ground stress. QJR Meteorol Soc 73:459-462

Montgomery RB (1948) Vertical eddy flux of heat in the atmosphere. J Meteorol 5:265-274. https://doi.org/ 10.1175/1520-0469(1948)005\%3c0265:VEFOHI\%3e2.0.CO;2

Neumann J (1964) Turbulent convection of turbulent kinetic energy in stratified shear flows. In: Sixth annual conference on aviation and astronautics, Tel Aviv and Haifa1964, pp 47-49 
Obukhov AM (1941) O raspredelenii energii v cpektre turbulentnogo potoka (on the spectral energy distribution in a turbulent flow). Izv AN SSSR, Ser Geogr Geofiz 5:453-466

Obukhov AM (1946) Turbulentnost' v temperaturnoj - neodnorodnoj atmosfere (turbulence in an atmosphere with a non-uniform temperature). Trudy Inst Theor Geofiz AN SSSR 1:95-115

Obukhov AM (1971) Turbulence in an atmosphere with a non-uniform temperature. Bound-Layer Meteorol 2:7-29. https://doi.org/10.1007/BF00718085

Paeschke W (1937) Experimentelle Untersuchungen zum Rauhigkeitsproblem in der bodennahen Luftschicht. Z Geophys 13:14-21

Poggendorf JC (1959) Biographisch-Literarisches Handwörterbuch der exakten Naturwissenschaten, Band VIIa, Teil 3: L-R, Berichtsjahre 1932-1953. Akademie-Verlag, Berlin, pp 80-81

Poggendorf JC (2003) Biographisch-Literarisches Handwörterbuch der exakten Naturwissenschaten, Band VIII, Teil 3, Doppellieferung 3/4. Wiley-VCH, Weinheim, pp 1794-1797

Prandtl L (1925) Bericht über Untersuchungen zur ausgebildeten Turbulenz. Z Angew Math Mech 5:136-139

Prandtl L (1932) Meteorologische Anwendung der Strömungslehre. Beitr Phys Freien Atm 19:188-202

Reynolds O (1895) On the dynamical theory of turbulent incompressible viscous fluids and the determination of the criterion. Phil Trans R Soc A186:123-164. https://doi.org/10.1098/rsta.1895.0004

Richardson LF (1920) The supply of energy from and to atmospheric eddies. Proc Roy Soc A 97:354-373. https://doi.org/10.1098/rspa.1920.0039

Robitzsch M (1942) Einige Gedanken über das Zustandekommen von Singularitäten im jährlichen und täglichen Gang meteorologischer Elemente. Meteorol Z 59:37-47

Rossby C-G, Montgomery RB (1935) The layer of frictional influence in wind and ocean currents, Contribution No. 71 from the Woods Hole Oceanographic Institution. Pap Phys Oceanogr Meteorol III 3:1-101. https://doi.org/10.1575/1912/1157

Schmidt W (1925) Der Massenaustausch in freier Luft und verwandte Erscheinungen. Henri Grand Verlag, Hamburg

Schwerdtfeger W, Lettau H (1986) The last two years of Z-W-G (Part 1, 2, 3). Weather. 41:129-131, 157$161,187-191$

Sheppard PA (1947) The aerodynamic drag of the Earth's surface and the value of von Karman's constant in the lower atmosphere. Proc R Soc A188:208-222. https://doi.org/10.1098/rspa.1947.0005

Skeib G (1980) Zur Definition universeller Funktionen für die Gradienten von Windgeschwindigkeit und Temperatur in der bodennahen Luftschicht. Z Meteorol 30:23-32

Stearns CR (1970) Conversion of profile difference quotients to true gradients at the geometric mean height in the surface layer. Bound-Layer Meteorol 1:146-154. https://doi.org/10.1007/BF00185736

Sutton OG (1953) Micrometeorology. McGraw Hill, New York

Sverdrup HU (1936) Austausch und Stabilität in der untersten Luftschicht. Meteorol Z 53:10-15

Taylor GI (1935) Statistical theory of turbulence, parts 1-4. Proc R Soc A151:421-478

Thornthwaite CW, Kaser P (1943) Wind gradient observations. Trans Am Geophys Union Meteorol 1:166-182

UAL University archive Leipzig, PA 687

Weickmann LA, Börngen M (2013) The Geophysical Institute 1923-1945. Heyday and Decline. In: Ehrmann W, Wendisch M (eds) Geophysics and meteorology at the University of Leipzig. Leipziger Universitätsverlag GmbH, Leipzig, pp 23-36

Wippermann F (1974) Laudation for the award of the Alfred Wegener Medal. unpublished

Yaglom AM (1990) Alexander Mikhailovich Obukhov, 1918-1989. Bound-Layer Meteorol 53:v-xi. https:// doi.org/10.1007/BF00122458

Zilitinkevich SS (1971) On the turbulence and diffusion under free convection conditions (in Russian). Izv. Akad. Nauk SSSR Ser Fiz Atmosf i Okeana 7:1263-1269

Publisher's Note Springer Nature remains neutral with regard to jurisdictional claims in published maps and institutional affiliations. 